\title{
The Rediscovery of the Guantánamo Striped Curlytail (Leiocephalus onaneyi)
}

Luis M. Díaz ${ }^{1}$ and Antonio Cádiz ${ }^{2}$

${ }^{1}$ Museo Nacional de Historia Natural de Cuba, Obispo \#61, esquina Oficios, Plaza de Armas, Habana Vieja, CP 10100 (zoryg@infomed.sld.cu) ${ }^{2}$ Facultad de Biología, Universidad de La Habana, Calle 25 \#455, Vedado, Ciudad de La Habana (cadiz@fbio.uh.cu)

Teiocephalus onaneyi was first described by Garrido (1973) Crom Loma de Macambo, a small limestone mountain, $-160 \mathrm{~m}$ in elevation, $-12 \mathrm{~km}$ west of Imías, Guantánamo Province, Eastern Cuba (20003'05"N, 74044'08"W). The original description was based on one female (holotype), a subadult male, and a juvenile (paratypes) collected by the botanist Onaney Muñiz. The species has been considered to be Critically Endangered (Rodríguez and Chamizo 1998) or "presumed to be extinct in the wild" (Rodríguez 1999).
Until now, no additional specimens had been collected. On 5 October 2010, we visited the type locality between 1100 and $1700 \mathrm{~h}$, and collected one adult female (Fig. 1) and a small juvenile (Fig. 2). We failed to find $L$. onaneyi on the mountain slopes, and only observed the species a few meters from the top, where the habitat is dominated by a combination of grass (Sporobolus sp., Poaceae), agaves (Agave sp.), and dense spiny bushes (Fig. 3). Garrido (1973) had commented that L. onaneyi was found exclusively on the top of Loma de

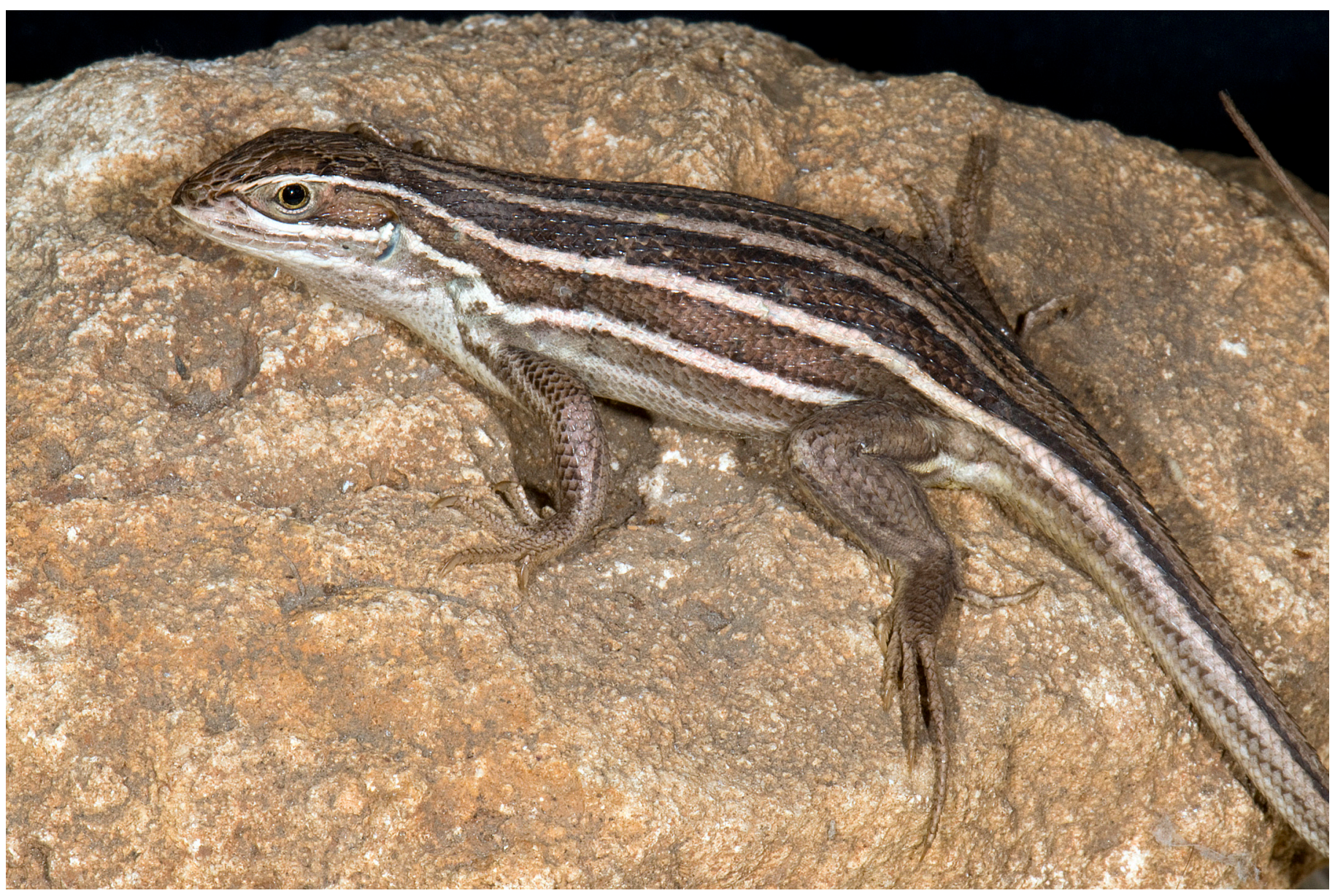

Fig. 1. Adult female Leiocephalus onaneyi (MNHNCu 4695). 


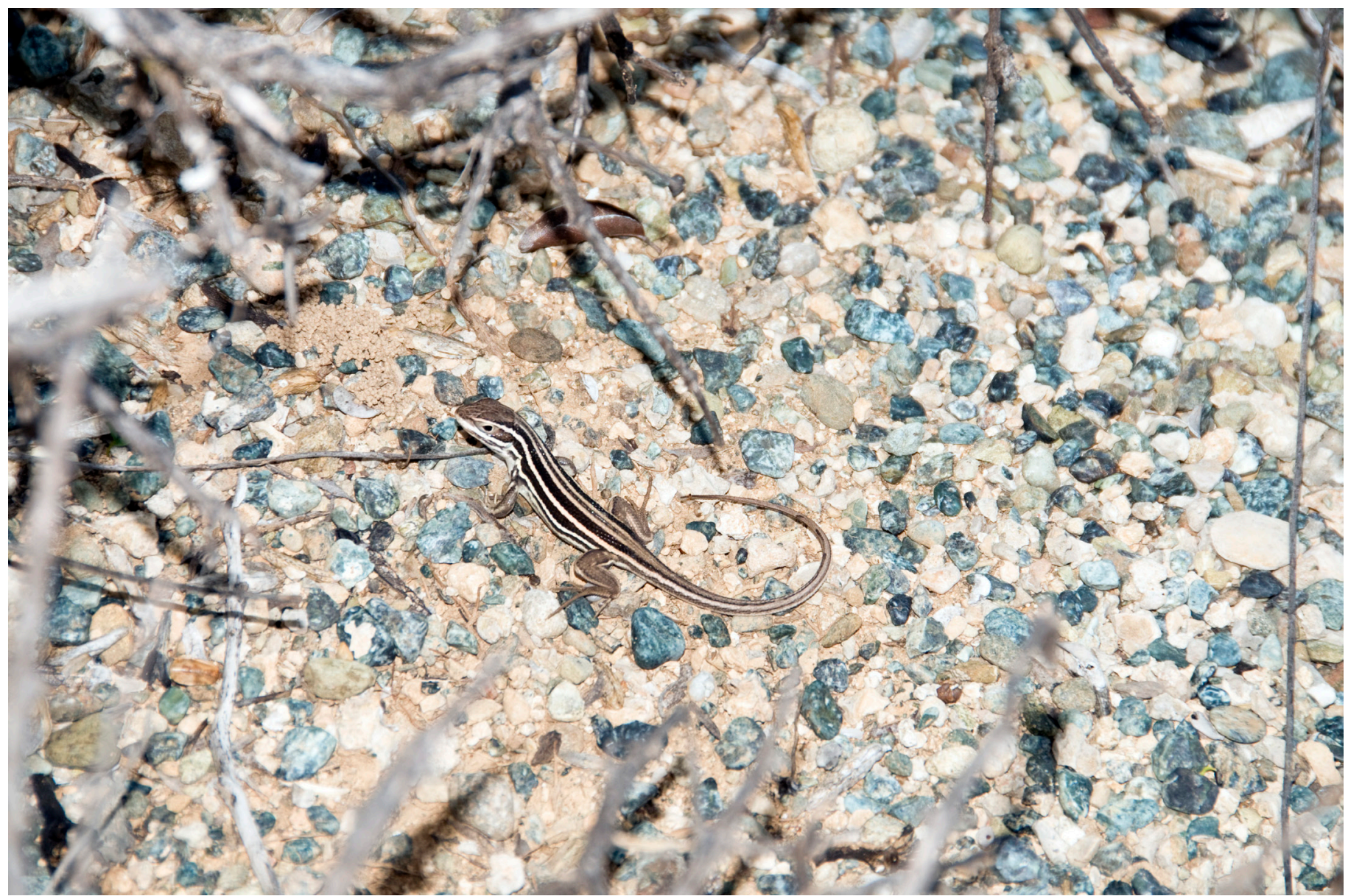

Fig. 2. Juvenile Leiocephalus onaneyi (MNHNCu 4696) in the field.

Macambo, where the vegetation was different from that on the slopes. He did not mention any association of the lizard with grasses, and only reported sharp rocks ("dogtooth limestone") as the main component of the habitat.

The juvenile (the first individual observed) was collected while crossing a narrow trail bordered by grass. Despite its small size, the presence of enlarged post-cloacal scales identified it as a male. The female was just a few meters away, and was gravid, with two palpable eggs in the abdomen. During attempts to noose it, this individual moved 3-4 m around a clump of agaves surrounded by grass, in which it repeatedly took refuge for short periods before emerging and continuing to move about the same area while avoiding our approach. In this particular area, sunshine was filtered through the cover of spiny bushes. An adult male (not captured) was observed basking on a log in a relatively open area. When disturbed by our presence, it ran quickly into nearby low and dense vegetation where we were unable to find it. A second juvenile (not captured) was similar in size and appearance to the first one, and was observed moving among grass and a dead agave. Air temperature at the locality was $37-40^{\circ} \mathrm{C}$ and maximum rela- tive humidity was $65 \%$. Captures and observations occurred between 1500 and $1600 \mathrm{~h}$.

Loma de Macambo supports the highest diversity of species in the genus Leiocephalus in Cuba (and possibly anywhere). In addition to L. onaneyi, L. carinatus, L. macropus, and $L$. raviceps are present, and all appeared to be more abundant than $L$. onaneyi. Future studies should be conducted to better understand the ecological partitioning in this lizard community, and also to search for $L$. onaneyi at other localities with similar habitats. The photographs included in this note are the first of living animals and their natural habitat. We did note evidence of two potential human-related threats, fires and goat farming. The locality has been proposed for protection, but no legal designation as a protected area has been approved.

Morphological data for the female were $70.5 \mathrm{~mm}$ SVL, $126.1 \mathrm{~mm}$ tail length, 54 dorsal scales from occiput to vent, 42 midbody scale rows, 6 supraoculars, and 4 loreals. For the juvenile male, SVL was $35.6 \mathrm{~mm}$, tail length $46.5 \mathrm{~mm}$ (with the very tip missing), 52 dorsal scales from occiput to vent, 44 midbody scale rows, 5 supraoculars, and 5 loreals. Parietals 




Fig. 3. Natural habitat of L. onaneyi on Loma de Macambo, Guantánamo Province, Cuba.

were in slight posterior contact on both specimens. Although the adult male we were unable to capture was slightly more ochreous on the lower flanks and throat than the female, the body was similarly striped in all individuals, with narrow white and cream light stripes alternating with chocolate brown (female) to almost black (juvenile) intervening zones. Both captured individuals had an immaculate grayish-white throat and belly. The new specimens of L. onaneyi were deposited in the collection of Museo Nacional de Historia Natural de Cuba (female: MNHNCu 4695; juvenile male: MNHNCu 4696).

\section{Acknowledgements}

Fieldwork was supported by the Systematic Research Fund of the Linnean Society of London and the Systematics Association (to LMD) and by the project "Ecology and
Evolution of Cuban Anoles," Tohoku University of Japan (to AC). We also thank the "Centro de Áreas Protegidas de Guantánamo" for support of our expedition, recognizing especially Yamilka Joubert, Rolando Villaverde, Gerardo Begué, and our driver, Rafael Ocaña. Orlando H. Garrido provided useful anecdotes and comments. Ramona Oviedo and Dasmiliá Cruz identified the plants. S. Blair Hedges and Kraig Adler reviewed the manuscript prior to submission.

\section{Literature Cited}

Garrido, O.H. 1973. Nueva especie de Leiocephalus (Lacertilia, Iguanidae) para Cuba. Poeyana (116):1-19.

Rodríguez Schettino, L. 1999. Introduction, pp. 1-16. In: L. Rodríguez, The Iguanid Lizards of Cuba. University Press of Florida, Gainesville.

Rodríguez Schettino, L. and A.R. Chamizo Lara. 1998. Reptiles cubanos con algún grado de amenaza de extinción. Poeyana (463):1-8. 